\title{
Synthesis, characterization and applications of polymer-metal chelates derived from poly[((4-acryloxy acetophenone)-divinylbenzene)] benzoyl hydrazone resins
}

\author{
THAMMISETTY RAVI SANKAR, K KESAVULU and PEDDAKOTLA VENKATA RAMANA* \\ Department of Chemistry, Sri Krishnadevaraya University, Anantapur 515 003, India \\ e-mail: ramanapv2103@yahoo.com
}

MS received 5 August 2013; revised 21 September 2013; accepted 14 December 2013

\begin{abstract}
Acryloxy acetophenone was prepared and subjected to suspension polymerization with divinylbenzene as a cross-linking agent. The resulting network polymer was ligated with benzoyl hydrazone. The functional polymer was treated with metal ions $[\mathrm{Cu}(\mathrm{II})$, Fe(II)]. The polymer-metal complexes obtained were characterized by elemental analysis, IR, $1 \mathrm{H}-\mathrm{NMR}$, solid state ${ }^{13} \mathrm{C}$ cross-polarization magic-angle spinning (CP/MAS) NMR, electron paramagnetic resonance (EPR), thermogravimetric and scanning electron microscopy (SEM) studies. The maximum uptake efficiency for the metal ions was determined. The reusability of the polymer ligand was tested and it was shown that even after four cycles, the efficiency of the uptake was not altered.
\end{abstract}

Keywords. 4-Acryloxy acetophenone; divinyl benzene; functionalized polymers; polymer-metal complexes; chemical modification; suspension polymerization; cross-linkage agent; network polymer.

\section{Introduction}

The interaction between metal ions and polymerized ligands may lead to the formation of coordination polymers in which the chelated metal ions are bounded by ligand molecules. ${ }^{1,2}$ Anchoring reagents to insoluble supports has come to be known as solid phase synthesis based on the pioneering efforts of Merrifield ${ }^{3}$ in polypeptide synthesis. Rapid developments now not only make polypeptide synthesis on polymer supports, but immobilized photosensitizers and immobilized transition metal complexes are also frequently reported. ${ }^{4}$ Polymer-metal complexes have been of interest to many chemists, because not only they are excellent models for metalloenzymes, but they have also led to developments in metal ion separation and recovery of metal ions. Increasing environmental concerns in waste-water treatment has led to the use of organic ligands anchored to solid supports in order to remove and recover important metal ions from aqueous solutions. ${ }^{5-7}$ Copolymers of activated meth(acrylates) have been utilized to synthesize macromolecular drug carriers. ${ }^{8}$ Wang et al. ${ }^{9}$ have indicated that the polymeric support and the polymeric end groups affect the catalytic activity and selectivity of these complexes in

\footnotetext{
*For correspondence
}

hydrogenation reaction. The complexes obtained from maleic acid-styrene, acrylic acid-vinyl pyrrolidone copolymers and nickel(II), platinum(II) and palladium(II) metal ions were found to be useful catalysts for the hydrogenation of 2-chloro-4-nitrotoluene, ${ }^{10}$ while copper(II) chelates synthesized from chloromethylated polystyrene were reported ${ }^{11}$ to catalyse Diels-Alder cyclization reactions. A survey of the literature reveals that hydrazones derived from low molecular weight aromatic ketones like acetophenone and benzophenone draw the attention of synthetic chemists due to their varied biological activities. ${ }^{12-14}$ Hydrazones also find their application in analytical chemistry. They act as multidentate ligands with metals forming coloured chelates. These chelates are then used in selective and sensitive determination of metal ions. ${ }^{15-19}$ With a view to the complexing abilities of hydrazone derivatives and in a program to develop selective resins, acetophenone hydrazone incorporated into the polymer, the 4-acryloxyacetophenone (AAP) cross-linked with divinylbenzene (DVB) was selected. The benzoyl hydrazine (BH) derivative of the cross-linked copolymer acts as insoluble polymeric ligand towards $\mathrm{Cu}$ (II) and $\mathrm{Fe}(\mathrm{II})$ ions. We report here the preparation, characterization and applications of hydrazone derivatives of poly[((AAP)-DVB)] towards $\mathrm{Cu}(\mathrm{II})$ and $\mathrm{Fe}(\mathrm{II})$ ions. The metal uptake efficiency and reusability of the resin are studied. 


\section{Experimental}

\subsection{Physico-chemical measurements}

Elemental analysis of the cross-linked copolymers and their metal complexes were carried out on Thermo Finningan FLASH EA 1112 CHNS analyzer. The IR spectra were recorded on Perkin-Elmer IR spectrophotometer model $983 \mathrm{G}$ using $\mathrm{KBr}$ pellets. ${ }^{1} \mathrm{H}$ and ${ }^{13} \mathrm{C}$ nuclear magnetic resonance (NMR) spectra of the samples were run on a dpx $200 \mathrm{MHz}$ in $\mathrm{CDCl}_{3}$ with tetramethylsilane (TMS) as internal standard. ${ }^{13} \mathrm{C}$ cross-polarization magic-angle spinning (CP/MAS) NMR spectra were recorded on a Bruker-dsx-300 MHz $\mathrm{CP} / \mathrm{MAS}$ at Indian Institute of Science, Bangalore. A Perkin Elmer model 3700 with TGA-7 computer and a Mettler TA 3000 system were used to evaluate the thermal stability and decomposition temperature of the copolymers and their metal complexes. EPR spectra of the copolymer metal complexes were recorded on varion E-4X band spectrophotometer at $303 \mathrm{~K}$. Particle size distribution of copolymer beads were studied with Malvern particle size analyzer by laser diffraction method. The sample was dispersed in paraffin oil. Scanning electron microscopy (SEM) was carried out using a JEOL-JSM 840 model. The copolymer was coated with gold. An ELICO UV-VIS SL 164 double beam spectrophotometer is used for absorbance measurements. The $\mathrm{pH}$ measurements were made with ELICO digital pH meter having a glass electrode model LI 127.

Standard salt solutions were prepared by taking requisite amounts in $50 \mathrm{ml}$ double distilled water and standardized by the known methods. ${ }^{20}$ Buffer solutions of $\mathrm{pH}$ range 3-6 were prepared from $1 \mathrm{M}$ acetic acid and $1 \mathrm{M}$ sodium acetate solution. Buffer solutions of $\mathrm{pH}$ range $8-10$ were prepared from $1 \mathrm{M}$ ammonium hydroxide and $1 \mathrm{M}$ ammonium chloride.

\subsection{Preparation of monomer}

To a solution of 4-hydroxyacetophenone $(0.2 \mathrm{~mol})$ in 2butanone, triethylamine (TEA) $(0.2 \mathrm{~mol})$ was added and stirred at $0-5^{\circ} \mathrm{C}$. Thermometer and mechanical stirrer and dropping funnel are arranged. To this mixture, acryloyl chloride $(0.2 \mathrm{~mol})$ in ether was added in a period of $60 \mathrm{~min}$. The condensation of acryloyl chloride with 4-hydroxyacetophenone liberates hydrochloride, which is adsorbed by TEA, which ultimately results into the quaternary salt (TEA hydrochloride). This quaternary salt is filtered and washed with ether and the filtrate collected. The filtrate which contains the monomer is washed with aqueous $5 \% \mathrm{NaOH}$ followed by water. Then the filtrate is extracted with ether and the solvent evaporated to get the monomer. The formation of AAP is confirmed by IR and ${ }^{1} \mathrm{H}$ NMR. The spectral data is consistent with the structure of monomer. m.p. $52-54^{\circ} \mathrm{C}$. IR $\left(\mathrm{cm}^{-1}, \mathrm{KBr}\right): 3022$ (Ar C-H stretching), 2934 (methylene $\mathrm{C}-\mathrm{H}$ stretching), 1745 (ester carbonyl), 1654 ( $\mathrm{C}=\mathrm{O}$ stretching in keto carbonyl) 1602 $(\mathrm{C}=\mathrm{C}$ skeletal vibration), 1165 (C-O stretching in ester) ${ }^{1} \mathrm{H}$ NMR $(\delta \mathrm{ppm}): 2.4(3 \mathrm{H}, \mathrm{s}, \mathrm{CH} 3-), 5.2-6.5(3 \mathrm{H}$, $\mathrm{CH} 2=\mathrm{CH}$ protons), 6.8 and $7.8(4 \mathrm{H}, \mathrm{Ar}-\mathrm{H})$.

\subsection{Polymerization of monomer}

Bead polymerization of the monomer $(30 \mathrm{~g})$ was carried out at $80 \pm 1^{\circ} \mathrm{C}$ using polyvinyl alcohol (PVA) as the stabilizer and BPO as catalyst in a four-necked reaction kettle fitted with a water condenser, a synchronized mechanical stirrer, a dropping funnel and a nitrogen inlet. A controlled stirring rate of $400 \mathrm{rpm}$ was maintained for $12 \mathrm{~h}$ DVB (5.2 g) was added as the cross-linking agent. The beads formed were filtered, washed with petroleum ether, 2-butanone, acetone, dichloromethane to remove the unreacted monomer and $\mathrm{f}$ inally with water to remove PVA. The product was dried in a vacuum oven at $30^{\circ} \mathrm{C}$ and obtained an yield of $68 \%$.

\subsection{Functionalization of polymer}

Functionalization of poly[((AAP)-DVB)] was achieved by incorporating benzoyl hydrazine $(\mathrm{BH})$ moiety through a post-polymerization reaction in a state of dispersion. Cross-linked polymer (5 g) and $\mathrm{BH}(10 \mathrm{~g})$ in dimethylformamide-water $\left(\mathrm{DMF}-\mathrm{H}_{2} \mathrm{O}\right)$ mixture (1:1) were placed in a $500 \mathrm{ml}$ round-bottomed flask and refluxed for $12 \mathrm{~h}$. The contents were filtered and the functionalized beads were collected, washed with DMF, ethyl acetate and water (scheme 1).

\subsection{Preparation of metal complexes}

$5 \mathrm{~g}$ of metal salts $\left(\mathrm{CuCl}_{2} \cdot 2 \mathrm{H}_{2} \mathrm{O}\right.$ or $\left(\mathrm{NH}_{4}\right)_{2} \mathrm{Fe}\left(\mathrm{SO}_{4}\right)$ $2.6 \mathrm{H}_{2} \mathrm{O}$, respectively, in a DMF- $\mathrm{H}_{2} \mathrm{O}(1: 1)$ were treated with $5 \mathrm{~g}$ of a functionalized polymer and refluxed for $10 \mathrm{~h}$ in double-distilled water at a $\mathrm{pH}$ of $6.9 \pm 0.1$. The reaction mixture was filtered and the resulting green $[\mathrm{Cu}(\mathrm{II})]$ and brown $[\mathrm{Fe}(\mathrm{II})]$ metallated polymers were washed in hot water, ethyl acetate, acetone and dried in a vacuum oven at $60^{\circ} \mathrm{C}$. 


\subsection{Physical properties}

Both the polymer metal complexes are insoluble in common organic solvents and non-hygroscopic in nature.

\subsection{Chemical analysis}

The metal contents in the polymer-metal complexes were estimated titrimetrically after acid treatment of the complexes. $^{20}$<smiles>C=CC(=O)Cl</smiles><smiles>CC[C@H](C)c1ccc([C@@H](C)[C@H](CCN)C(=O)Oc2ccc(C(C)=O)cc2)cc1</smiles><smiles>C=CC=O</smiles><smiles>CC(C)CC(C)C</smiles>

(i)<smiles>NNC(=O)c1ccccc1</smiles>

(ii)DMF- $\mathrm{H}_{2} \mathrm{O}(1: 1)$

$\mathrm{H}_{3} \mathrm{C}$<smiles>O=C1CCCCC1</smiles>

(i)DVB

(ii)BPO, PVA

(iii) $80 \pm 1^{\circ} \mathrm{C}$, $400 \mathrm{rpm}, 12 \mathrm{~h}$

$$
\text { (1) }
$$


Table 1. Elemental analysis of poly[((AAP)-DVB)], poly[((AAP)-DVB)]-BH functionalized polymer and metal chelates.

Found $\%$

Element $\overline{P o l y[((A A P)-D V B)] ~ P o l y[((A A P)-D V B)]-B H ~ P o l y[((A A P)-D V B)]-B H ~-C u(I I) ~ P o l y[((A A P)-D V B)]-B H ~-F e(I I) ~}$

\begin{tabular}{lcccc}
\hline $\mathrm{C}$ & 68.95 & 71.62 & 69.37 & 67.26 \\
$\mathrm{H}$ & 6.27 & 6.73 & 6.52 & 6.37 \\
$\mathrm{~N}$ & - & 4.58 & 1.64 & 1.73 \\
Metal & - & - & 1.75 & 1.58 \\
& & $\mathbf{5 2}^{*}$ & & \\
\hline
\end{tabular}

*indicates the percentage of conversion

\section{Results and discussion}

\subsection{Elemental analysis}

Elemental analysis data is presented in table 1. The data show that the conversion of keto carbonyl groups to hydrazone function was $52 \%$ by weight (only the surface keto groups were converted to benzoyl hydrazone). The remaining keto groups, deeply buried in the polymer chains were unaffected. Metallation was 28 and $30 \%$, respectively for $\mathrm{Cu}(\mathrm{II})$ and $\mathrm{Fe}(\mathrm{II})$ complexes.

\subsection{IR spectral studies}

The IR spectrum of poly[((AAP)-DVB)] copolymer shows absorption band at around $2929 \mathrm{~cm}^{-1}$, which has been identified as - $\mathrm{CH}$ backbone methylene stretching vibrations. The ester carbonyl is identified through the appearance of a strong absorption band at $1732 \mathrm{~cm}^{-1}$. A strong absorption around $1600 \mathrm{~cm}^{-1}$ is due to $\mathrm{C}=\mathrm{C}$ stretching vibration of the phenyl rings. The $(\mathrm{C}-\mathrm{O}-$ C) stretching vibrations in compound are confirmed by a band at $1170 \mathrm{~cm}^{-1}$. The keto carbonyl functionality is identified by a sharp absorption band around $1651 \mathrm{~cm}^{-1} \cdot{ }^{21-23}$ The formation of hydrazone is confirmed by a set of distinct vibrations at 3350 and $1632 \mathrm{~cm}^{-1}$ which are due to $-\mathrm{NH}$, and $\mathrm{C}=\mathrm{N}$ stretching, respectively. The disappearance of the band at $1651 \mathrm{~cm}^{-1}$ indicates the removal of carbonyl function of ketone units. The appearance of a new absorption band at $1685 \mathrm{~cm}^{-1}$ is due to $\mathrm{C}=\mathrm{O}$ group of benzoyl hydrazine moiety with a shoulder at $1660 \mathrm{~cm}^{-1}$. The shoulder that appears at $1660 \mathrm{~cm}^{-1}$ is due to the inner keto groups present in poly[((AAP)-DVB)] copolymer. The FTIR spectra of poly[((AAP)-DVB)] copolymer and its benzoyl hydrazine functionalized resins are shown in figure 1 . The $\mathrm{Cu}(\mathrm{II})$ complex shows peak at $1602 \mathrm{~cm}^{-1}$, which are lowered from $1632 \mathrm{~cm}^{-1}(\mathrm{C}=\mathrm{N}$ str.), in functionalized resin. Amide group vibrations increase in frequency from 1505 to $1520 \mathrm{~cm}^{-1}$. These changes in amide group vibrations suggest amide oxygen coordination in keto form. The band observed at around $590 \mathrm{~cm}^{-1}$ is assigned to $v_{\mathrm{Cu}-\mathrm{N}}$ vibrations. It is therefore inferred that the ligands coordinate in bidentate fashion. The IR spectrum of functionalized copolymer shows intense band at $1651 \mathrm{~cm}^{-1}$ due to $\mathrm{C}=\mathrm{O}$ stretching in hydrazone and its downward shift in $\mathrm{Fe}$ (II) complex suggest coordination of metal ion through oxygen atoms. There is a downward shift of $\mathrm{C}=\mathrm{N}$ vibration of azomethine from 1632 to $1610 \mathrm{~cm}^{-1}$ which indicates the coordination of azomethine nitrogen atom. Thus, in each complex the metal atom binds to the ligand through azomethine nitrogen and hydrazone carbonyl oxygen atoms.
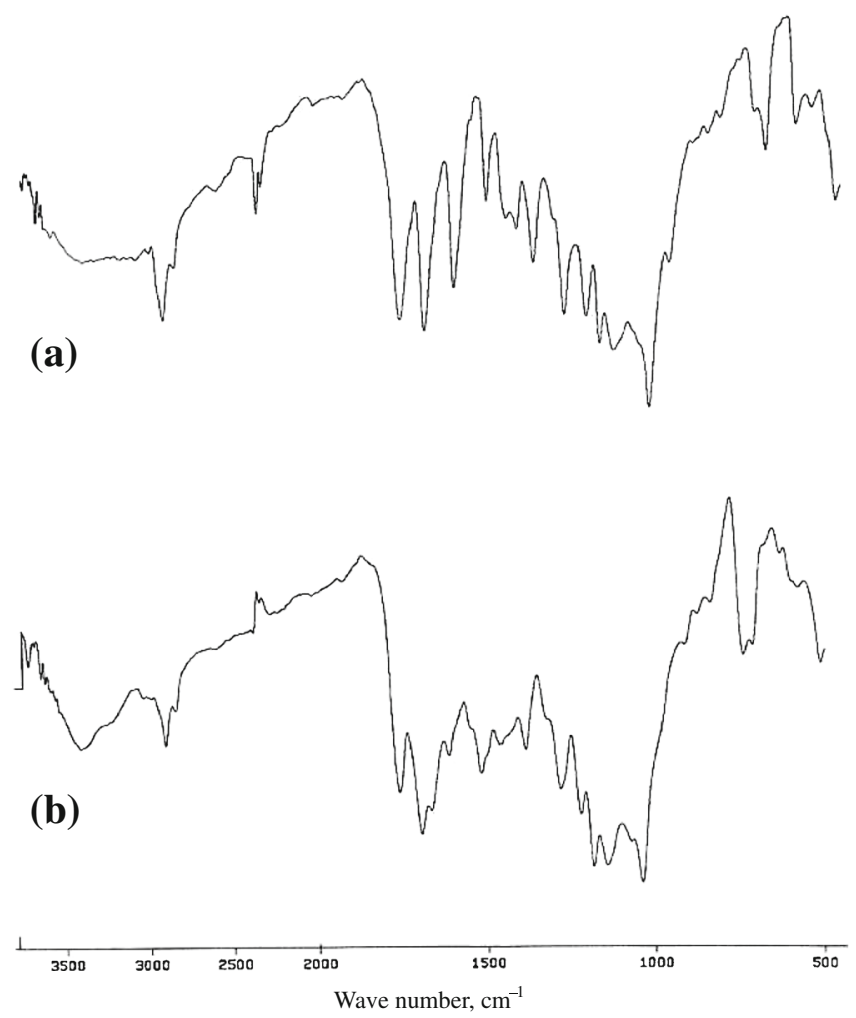

Figure 1. FTIR spectra of (a) poly[((AAP)-DVB)]; (b) poly[((AAP)-DVB)]-BH resins. 


\subsection{Solid State ${ }^{13}$ C CP-MAS NMR spectroscopy}

In the present investigation in addition to elemental analysis and FT IR spectroscopy, ${ }^{13} \mathrm{C}$ CP-MAS $\mathrm{NMR}^{24-26}$ is used for identifying the polymer units. The sample is spun at two different spins and by comparing the two spectra, the spinning side bands are eliminated. The ${ }^{13} \mathrm{C}$ CP-MAS of cross-linked copolymer has been compared with its soluble homopolymer analogue. Proton decoupled spectra of homopolymer is taken in $\mathrm{CDCl}_{3}$ solution. The ${ }^{13} \mathrm{C}$ NMR spectra of AAP homopolymer and ${ }^{13} \mathrm{C} \mathrm{CP}-\mathrm{MAS}$ of crosslinked copolymers are shown in figures 2 and $3 \mathrm{a}$, respectively. The backbone ${ }^{1} \mathrm{C}$ and ${ }^{2} \mathrm{C}$ carbons of homopolymer appeared as clear distinct lines at 46.15 and $37.93 \mathrm{ppm}$, respectively. In the case of cross linked copolymer, the intense peak at 41.17 is attributed to the backbone carbons. Because of the residual broadening, the peaks due to methylene and methyl carbons are not clearly resolved. The ketonic carbonyl of AAP appeared at $198.71 \mathrm{ppm}$ as sharp intense line in homopolymer, whereas in cross-linked polymer it appeared at $196.72 \mathrm{ppm}$ as a medium intense peak. The phenyl ester carbonyl ${ }^{27}$ gave sharp line at $175.21 \mathrm{ppm}$ in homopolymer and as a sharp peak in cross-linked system at $172.59 \mathrm{ppm}$. The ${ }^{4} \mathrm{C}$ of phenyl ring appeared at $154.68 \mathrm{ppm}$. The ${ }^{5} \mathrm{C}$ and ${ }^{9} \mathrm{C},{ }^{6} \mathrm{C}$ and ${ }^{8} \mathrm{C}$ aromatic carbons of homopolymer gave sharp lines at 134.64 and $129.92 \mathrm{ppm}$. The line observed at $135.54 \mathrm{ppm}$ is attributed to ${ }^{7} \mathrm{C}$ of aromatic ring. In the case of ${ }^{13} \mathrm{C} \mathrm{CP}-$ MAS NMR, because of residual broadening the clear splitting of aromatic signals are not observed. The aromatic carbons of solid sample gave only a sharp intense line at $129.29 \mathrm{ppm}$ with a shoulder at $122.45 \mathrm{ppm}$.
The ${ }^{13} \mathrm{C}$ CP-MAS NMR spectrum of benzoyl hydrazone derivative of poly[((AAP)-DVB)] [cf. figure 3b] shows an intense peak at 41.44 is attributed to the backbone carbons. The aromatic carbons of solid sample gave only a sharp intense line at $128.25 \mathrm{ppm}$ with a shoulder at $122.86 \mathrm{ppm}$. The phenyl ester carbonyl gave medium intense peak at $173.62 \mathrm{ppm}$. The disappearance of peak at $196.72 \mathrm{ppm}$ indicates the absence of ketonic carbon atom of acetophenone unit. This clearly explains the formation of benzoyl hydrazone derivative. Due to residual broadening, a clear separation of the signals is not observed in the spectrum.

\subsection{EPR spectroscopy}

EPR parameters gave a measure of the nature of the complexation with the metal ion. Anisotropic spectra are obtained for polychelates in crystalline state at $303 \mathrm{~K}$. The $\mathrm{g}_{\|}$and $\mathrm{g}_{\perp}$ are computed from the spectra using DPPH free radical as g marker. For the covalent complexes, $\mathrm{g}$ is less than 2.3 and for ionic environment it is normally 2.3 or larger. ${ }^{28}$ The values $g_{\|}$and $\mathrm{g}_{\perp}$ for $\mathrm{Cu}(\mathrm{II})$ complex was 2.20 and 2.04 , thereby indicating covalent character for the metal-ligand bond in the complex. The EPR signal corresponding to Fe(II) complex is not observed.

A survey of the literature reveals that $\mathrm{Cu}$ (II) and NI(II) metal complexes of poly(salicylaldehyde acrylate)-divinylbenzene semicarbazone resin ${ }^{29}$ exhibit paramagnetic property. The nature of metal-ligand bond was reported to be covalent in these complexes. Similarly, Ni(II) complex of poly(2-hydroxy-4methacryloyloxy acetophenone-formaldehyde) was

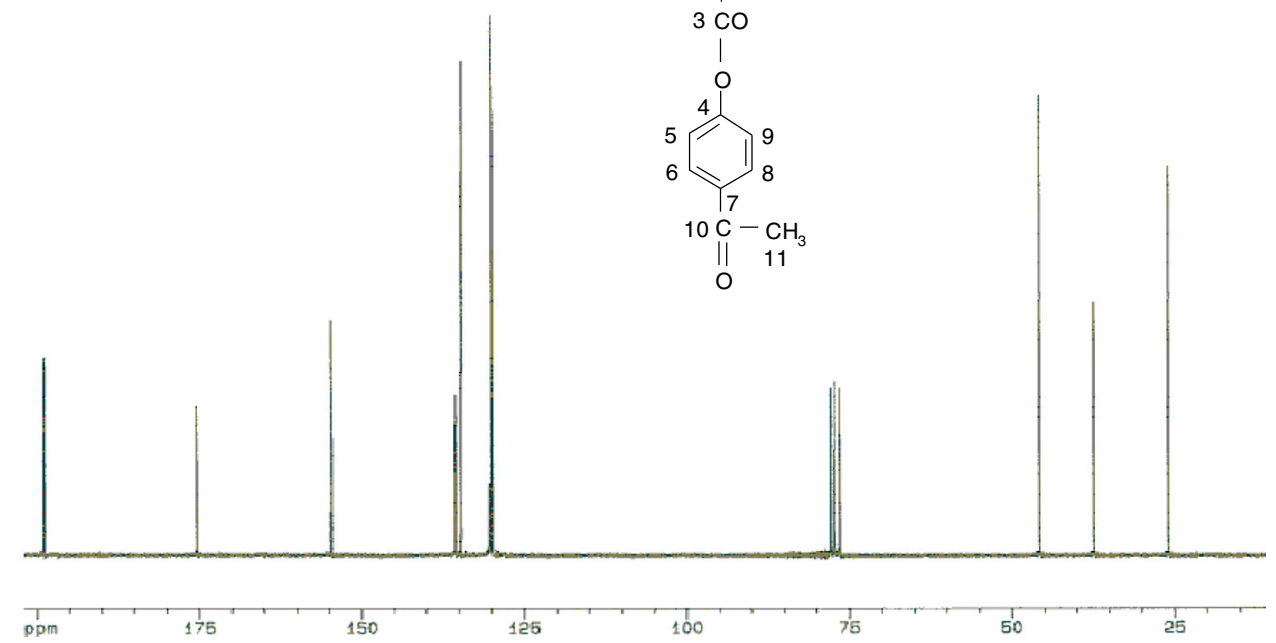

Figure 2. ${ }^{13} \mathrm{C}$ NMR spectrum of poly(4-acryloxy acetophenone) [homopolymer]. 

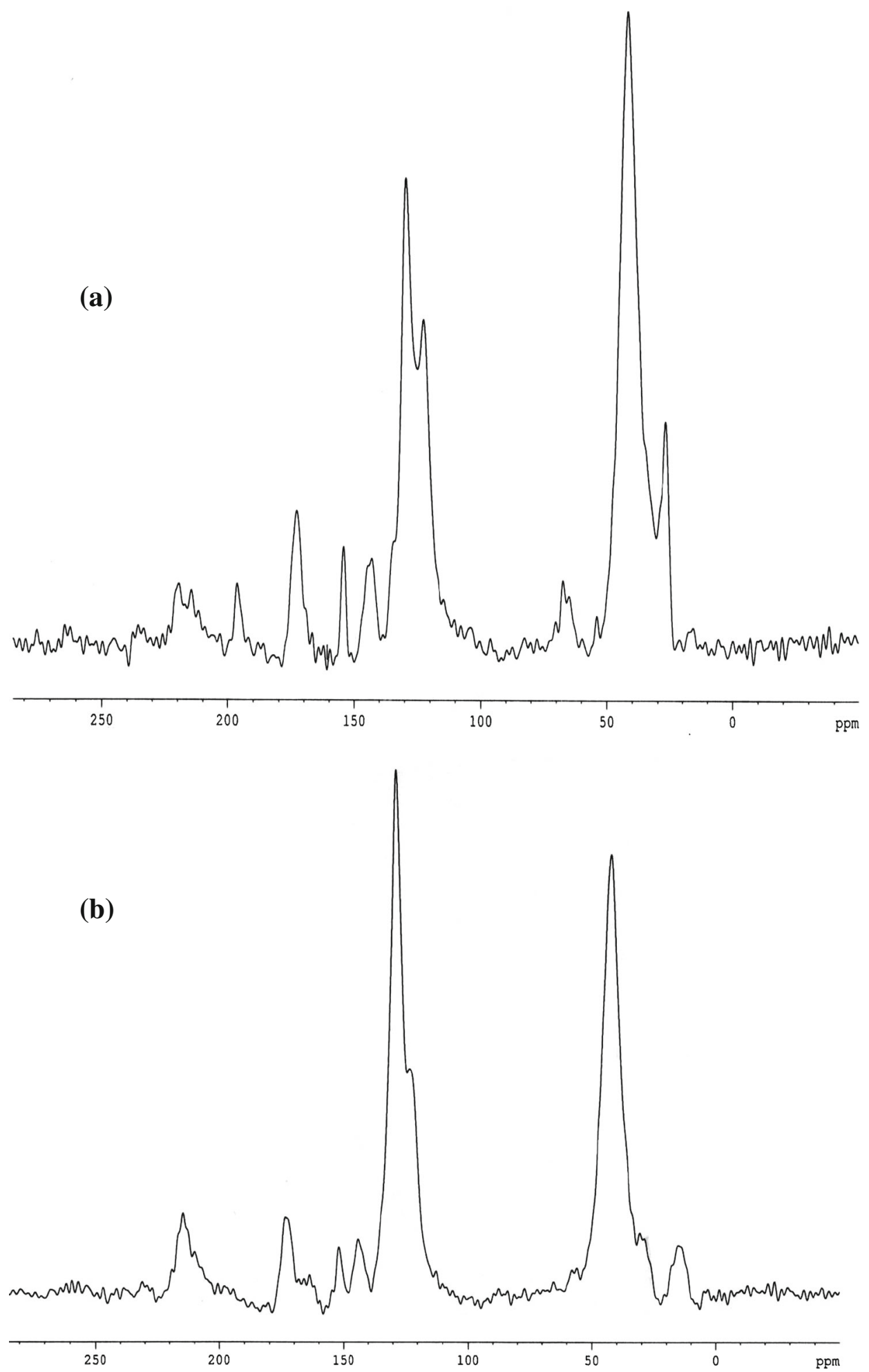

Figure 3. ${ }^{13} \mathrm{C}$ CP-MAS of (a) poly[((AAP)-DVB)]; (b) poly[((AAP)-DVB)]-BH resins.

also reported ${ }^{30}$ to exhibit paramagnetic behaviour with a distorted octahedral geometry. ${ }^{31}$ Hence, based on the covalent nature of the metal-ligand bond observed in the present studies and also based on the reports made in the literature, ${ }^{29-31}$ octahedral geometry is suggested for the complexes.

\subsection{Thermogravimetric analysis}

In order to study the thermal stability and decomposition pattern of cross-linked copolymers, dynamic thermogravimetric analysis is under taken ${ }^{32}$ and the data presented in the table 2 and thermograms are shown 
Table 2. TG data of poly[((AAP)-DVB)], poly[((AAP)-DVB)]-BH functionalized polymer and metal chelates.

\begin{tabular}{lllllllllllll}
\hline & & \multicolumn{8}{c}{ Weight loss $(\%)$ at temperature $\left({ }^{\circ} \mathrm{C}\right)$} \\
\cline { 3 - 13 } Sl. no. & System & IDT's & 250 & 300 & 350 & 400 & 450 & 500 & 550 & 600 & 650 & 700 \\
\hline 1 & Poly[((AAP)-DVB)] & 176 & 7.8 & 12.5 & 27 & 50 & 61.7 & 80.8 & 90 & 91.8 & 96 & - \\
2 & Poly[((AAP)-DVB)]-BH & 220 & 6.4 & 15 & 25.5 & 45 & 55.7 & 80 & 89 & 91.5 & 94 & - \\
3 & Poly[((AAP)-DVB)]-BH-Cu(II) chelate & 290 & 4.7 & 9 & 29.5 & 71.4 & 78 & 82 & 84 & 91 & 94 & 96 \\
4 & Poly[((AAP)-DVB)]-BH-Fe(II) chelate & 295 & 5.4 & 10.4 & 27.5 & 76 & 80 & 89.5 & 92 & 95 & 97 & 98 \\
\hline
\end{tabular}

in figure 4. The thermograms of the copolymer and its functionalized resins are run in air atmosphere. The degradation of poly[((AAP)-DVB)] occurred in two stages. The first stage decomposition is observed from 176 to $444^{\circ} \mathrm{C}$ and the weight loss found was $60 \%$. The second stage degradation of the copolymer resin was in the temperature range of $444-604^{\circ} \mathrm{C}$. The weight loss involved in this stage was $27.7 \%$.

The $\mathrm{BH}$ derivative also decomposed in a two-stage process. The first stage of decomposition commenced at $220^{\circ} \mathrm{C}$ and was completed at $430^{\circ} \mathrm{C}$. The initial weight loss is $53 \%$. The second stage of decomposition was in the temperature range 430 and $594^{\circ} \mathrm{C}$ and the weight loss was $45.6 \%$.

The thermal degradation data of $\mathrm{BH}$ functionalized poly[((AAP)-DVB)] $\mathrm{Cu}$ (II) and $\mathrm{Fe}(\mathrm{II})$ metal complexes is presented in table 2 . The initial decomposition data of $\mathrm{Cu}$ (II) and $\mathrm{Fe}$ (II) complexes are 290 and $295^{\circ} \mathrm{C}$, respectively. The degradation occurs mainly in two stages and decomposition is fast up to $400^{\circ} \mathrm{C}$. The first stage of decomposition is due to the rupture of weak linkages and volatilization of low molecular weight fragments. The second slow decomposition of chelates at higher temperatures may be due to the breakage of main

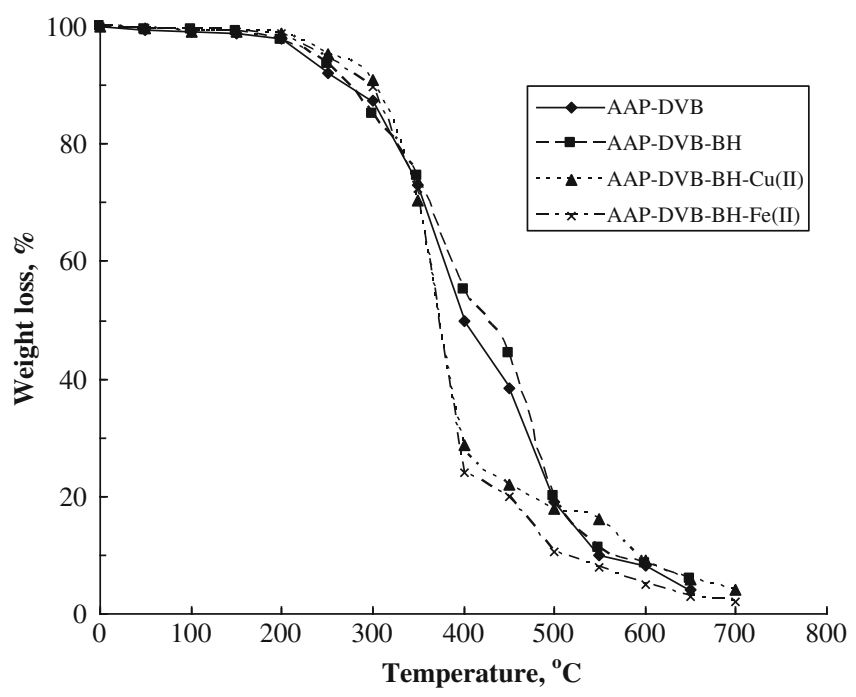

Figure 4. Thermogravimetric curves. chain accompanied by the volatilization of the cleaved products.

\subsection{Particle size analysis}

The success and reproducibility of the suspension polymerization is determined by measuring the average particle size of the beads formed. ${ }^{33,34}$ The particle size distribution of the AAP-DVB copolymer is determined by Malvern particle size analyzer. The different classes of the particle sizes and percentage bands of the particles are presented in table 3 . The average particle size of the system is $86.12 \mu \mathrm{m}$ and the distribution curve is relatively broad. The particle size distribution curve is shown in figure 5 .

\subsection{Scanning electron microscopy}

SEM is the technique employed for studying the shape, size and morphological features of the polymers in beaded form. ${ }^{35-37}$ The SEM photographs are presented in figure 6. The SEM photographs of $\mathrm{BH}$ functionalized AAP-DVB $\mathrm{Cu}$ (II) and $\mathrm{Fe}$ (II) metal complexes are shown in figures $6 \mathrm{c}$ and d. Functionalized resin appears smoother [cf. figure 6b] than that of the metal anchored resins. The rough appearance of the resin surface in due to the result of the doping of the metal ions. The copolymer beads [cf. figure 6a] were spherical and of various sizes. The beaded nature of the polymer confirms the success of suspension polymerization.

\subsection{Applications}

The time course of resin-metal interaction is of considerable importance if the resin is to be used in a dynamic system such as a packed column or a flowing system. If complexation is not sufficiently rapid for certain metal ions, then their retention on a column will be low owing to the short contact time between the resin and solution. Thus, absorption of resin should be examined over an extensive period. Slow exchange rates of many chelating resin have been reported ${ }^{38,39}$ to prevent their 
Table 3. Particle size analysis of poly[((AAP)-DVB)] copolymer.

\begin{tabular}{|c|c|c|c|c|c|c|c|c|c|c|c|}
\hline She (umi) & Vol Undier \%/ & SyE (juाt) & Vol Lnithe 8 & 5 log (jin) & Vol Џnder $x$ & $6 z 0(\mu \pi)$ & Vol Lnot th & Siln finim) & Voi Undes & $5 i 20(4 \mathrm{~m})$ & Voi Undor s: \\
\hline 0.010 & 0.00 & $126 \%$ & 7,74 & 24.91 & 12.83 & 44.675 & 24.71 & 128.191 & 7806 & 622.451 & 100,00 \\
\hline 4200 & 1000 & 12704 & 7 柺 & 2440 & 13.08 & 48,862 & 27,184 & 141,560 & 34.17 & 70.627 & 100.00 \\
\hline 1,466 & 0.69 & 13.760 & 1.44 & 22.960 & 13.30 & 51,380 & 28.69 & 150.680 & 87.06 & 78.214 & 100,00 \\
\hline 1888 & 0,85 & 13900 & B.53 & 22010 & 13.41 & 56.368 & 32,48 & 158.860 & 8934 & 863.367 & $\{90,05$ \\
\hline 3405 & 219 & 19.810 & B.53 & 24,892 & 14,10 & 6000 & 35.14 & 178.260 & 99.43 & 1002334 & $100,0 \mathrm{c}$ \\
\hline 3.612 & 228 & $14: 00$ & 868 & 25.125 & 14,35 & 7000 & 42, 89 & 200000 & 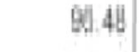 & 1124.605 & 100.00 \\
\hline 4.172 & 2.59 & 14.230 & 172 & 25.179 & 14.89 & 70 ifto & 43,42 & 224.44 & A8. 41 & 1281.915 & 100,00 \\
\hline 4. 286 & 302 & 14,250 & 8.79 & 30,000 & 16,84 & 76.000 & 46.47 & 251785 & $B A$ & 441582 & 100.60 \\
\hline 6.026 & 307 & 1460 & 9.12 & 31,070 & 17,69 & 79.021 & 4989 & 28250 & 100,00 & 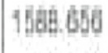 & 100.60 \\
\hline 6.407 & 3.34 & $15.26 \mathrm{~J}$ & 9.32 & 37,000 & 20.95 & 85,405 & 54.14 & 315.979 & 100.00 & 1762.502 & 100.00 \\
\hline 3.656 & 343 & 15.530 & 0.49 & 3.260 & 20.89 & 99,337 & 50.92 & 365.86 id & 100.00 & 200000 & 100.40 \\
\hline 8.84 & 5.69 & $15 B 87$ & 9.69 & 38.850 & 21,08 & 97,300 & 02.28 & 398.052 & 100.00 & & \\
\hline 11,630 & 713 & 18121 & 10.61 & $38.0 \%$ & 21.75 & 100.000 & 64.60 & 467744 & 1000 & & \\
\hline 11.697 & 7.36 & 10.275 & 11.51 & 49.000 & 21,81 & 112.490 & 7131 & 502377 & 10800 & & \\
\hline 12.225 & 750 & 20000 & 11.68 & 42,800 & 2220 & 125,000 & 77.64 & 963677 & 100.00 & & \\
\hline
\end{tabular}

commercial use. The rate of complexation depends on the chemical nature of the metal ion and the ligand, as well as the structure of the polymer matrix. The steric constraints in a dense macromolecular matrix lower the reactivity of ligand function.

In order to optimize the time required for complexation towards $\mathrm{Cu}$ (II) and $\mathrm{Fe}(\mathrm{II})$ ions, batch studies were carried out. ${ }^{40}$ The time dependence of the complexation of $\mathrm{Cu}$ (II) and $\mathrm{Fe}$ (II) by the functionalized AAP-DVB resin was followed by the change in the concentrations of the metal-salts solutions at regular intervals. The data is presented in the figure 7.

Experiments show that the resin is capable of binding with metal ions such as $\mathrm{Cu}^{2+}, \mathrm{Fe}^{2+}, \mathrm{Ni}^{2+}$ and $\mathrm{Co}^{2+}$

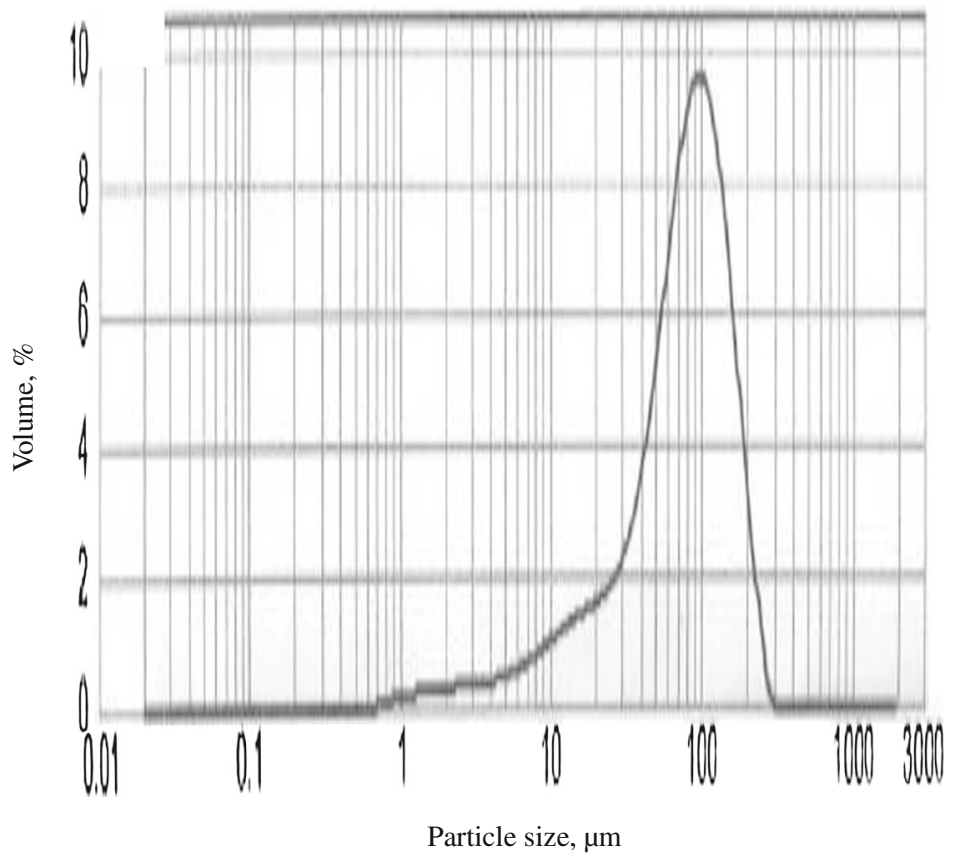

Figure 5. Particle size distribution of poly[((AAP)-DVB)] copolymer beads. 


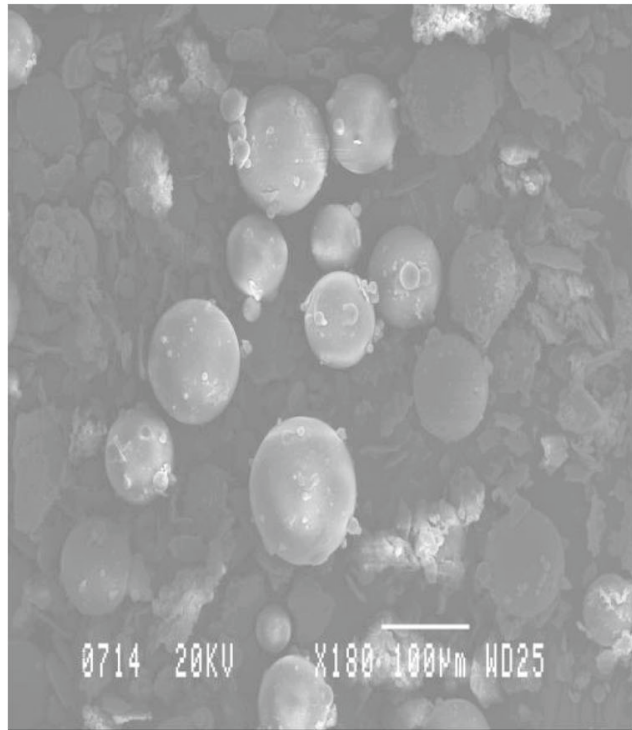

(a)

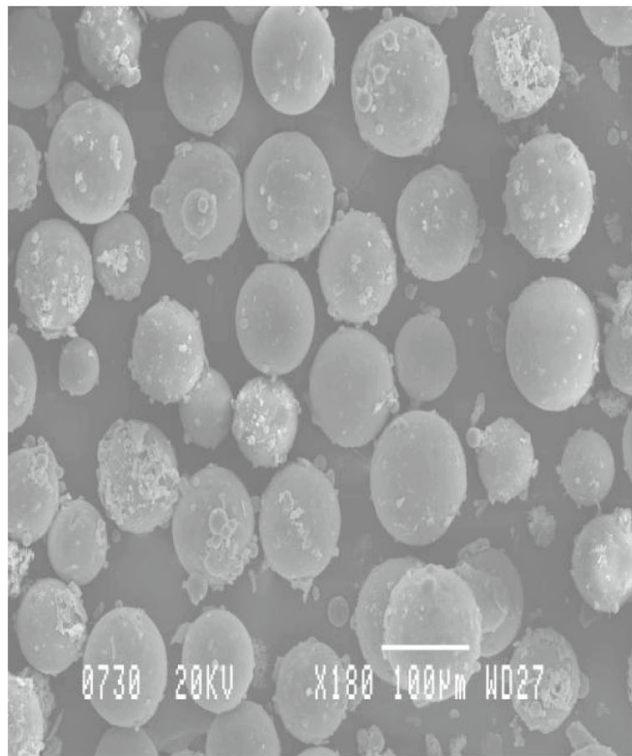

(c)

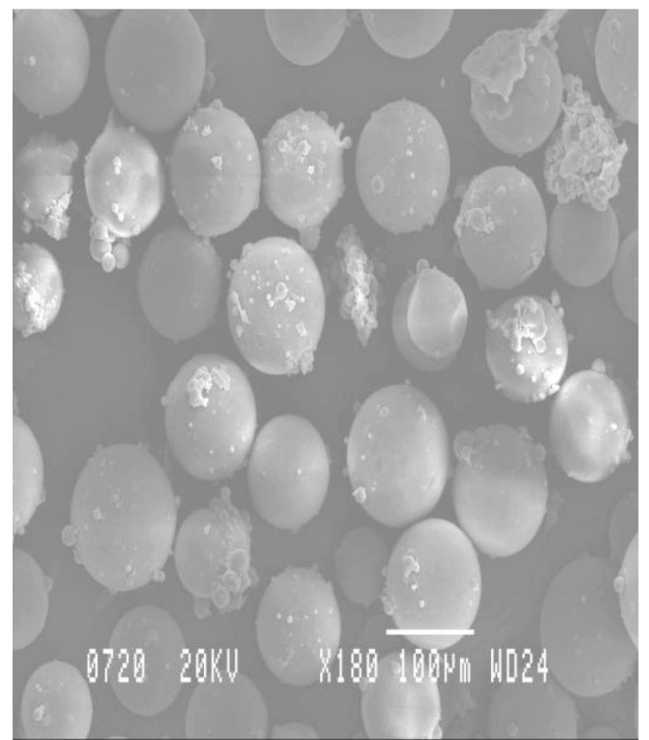

(b)

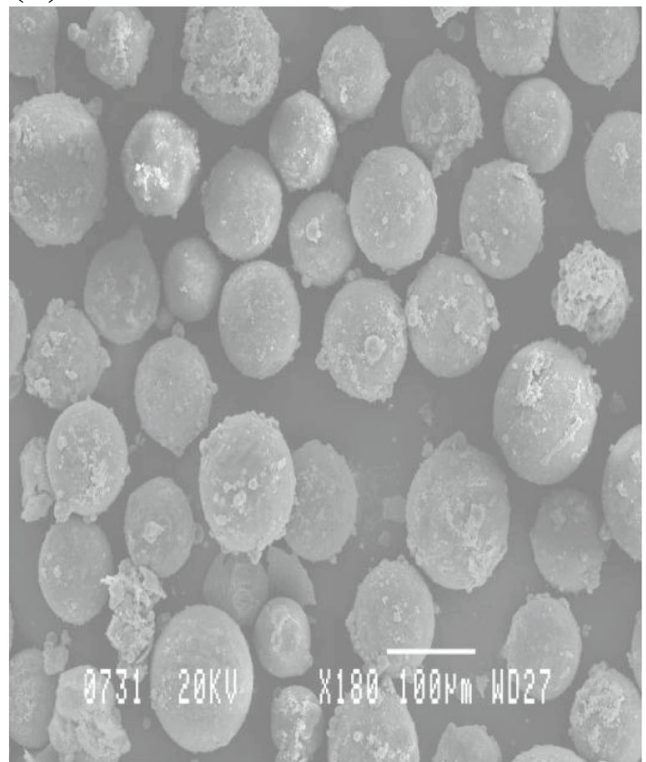

(d)

Figure 6. SEM photographs of (a) poly[((AAP)-DVB)], (b) poly[((AAP)-DVB)]-BH functionalized resin, (c) poly[((AAP)-DVB)]-BH Cu(II) complex and (d) poly[((AAP)-DVB)]$\mathrm{BH} \mathrm{Fe}(\mathrm{II})$ complex.

ions. The complexation of $\mathrm{Cu}(\mathrm{II})$ and $\mathrm{Fe}(\mathrm{II})$ was completed in 50 and $60 \mathrm{~min}$ for functionalized resin. The resin is also capable of binding with $\mathrm{Ni}^{2+}$ and $\mathrm{Co}^{2+}$ ions but with a lesser \% uptake. The time taken for the maximum uptake of $\mathrm{Ni}^{2+}$ and $\mathrm{Co}^{2+}$ ions is found to be 30 and $40 \mathrm{~min}$, respectively. The percentage of metal ion taken up is found to be 11 and $14 \%$, respectively for $\mathrm{Ni}^{2+}$ and $\mathrm{Co}^{2+}$ ions. But in the present study the studies are restricted to $\mathrm{Cu}^{2+}$ and $\mathrm{Fe}^{2+}$ ions only that have greater $\%$ of uptake by the functionalized resin. Chelation of $\mathrm{Cu}(\mathrm{II})$ and $\mathrm{Fe}(\mathrm{II})$ is possible in the presence of other common ions present in waste water.

\subsection{Effect of $p H$ on uptake of metal ion}

To various buffer solutions ( $\mathrm{pH}$ 3-10), metal ion [Cu(II), $\mathrm{Fe}$ (II) (0.1) bulk concentration], functionalized AAP-DVB resin $(5 \mathrm{~g})$ was added and maintained under shaking for $90 \mathrm{~min}$. The metallated beads were filtered and thoroughly washed. The bound metal ion was released by acid treatment and the metal content determined titrimetrically is presented in figure 8 . From the plots, it can be concluded that the change in $\mathrm{pH}$ has relatively little effect on the uptake of metal ions by the functionalized resin. The reason for this is that the 


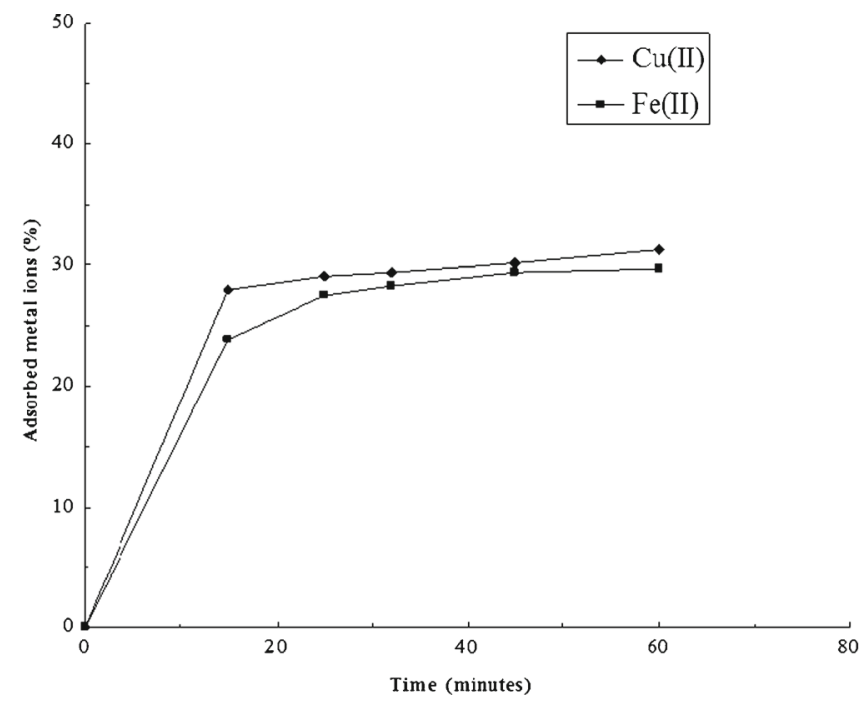

Figure 7. $\mathrm{Cu}(\mathrm{II})$ and $\mathrm{Fe}(\mathrm{II})$ uptake by the functionalized poly[((AAP)-DVB)] average of three determinations.

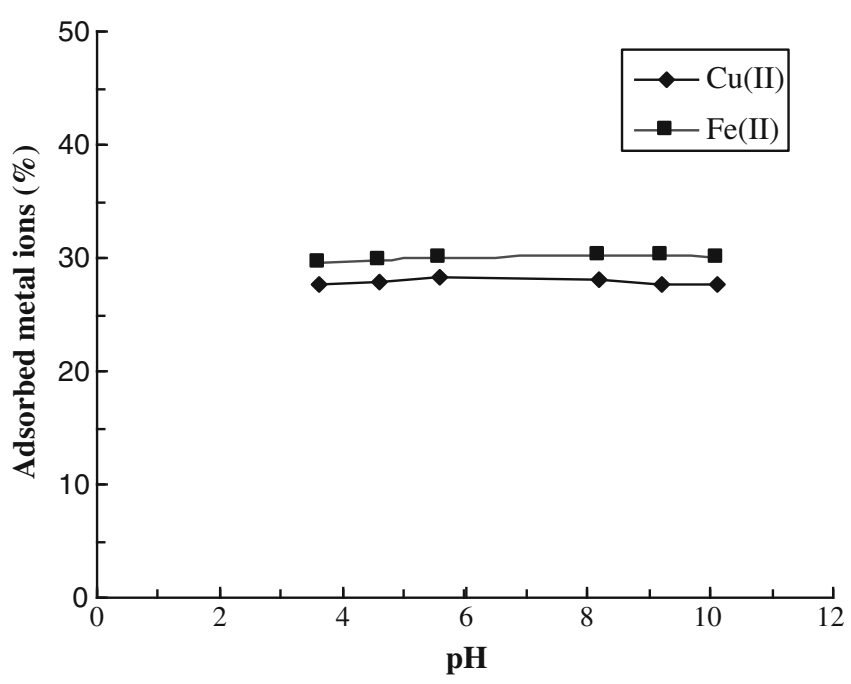

Figure 8. Effect of $\mathrm{pH}$ on adsorption of metal ions $\mathrm{Cu}$ (II) and $\mathrm{Fe}(\mathrm{II})$ average of three determinations. chelation of atoms mainly depends on the structural features of the ligand and may be influenced by the $\mathrm{pH}$ of the medium. Hydrazones can exit either in keto form or in an enol form. In acid solution the nitrogen atom of hydrazone in keto form, may be protonated which may affect the formation of complex, as the same nitrogen atom is involved in chelation with metal ion. In alkaline solutions the enol form may be in anionic form and coordinate with the metal ion. But in the present study, the $\mathrm{pH}$ of the solution has negligible effect as the hydrazone moiety is in a polymer matrix and change in the structural features of the hydrazone based on the changes in the $\mathrm{pH}$ has little effect on complexation. Hence, the effect of change in the hydrogen ion concentration or hydroxyl ion concentration has only little effect and does not influence the extent of chelation much.

The uptake of metal ions by the present resin is compared with that of the poly(4-acryloxybenzophenone thiosemicarbazone)-divinylbenzene resins that were reported in the literature. ${ }^{41}$ The comparative results are presented in table 4.

The results show that the time taken for the maximum uptake of metal ions by the present resins are much lower than that of poly(4-acryloxybenzophenone thiosemicarbazone)-divinylbenzene resins.

In the case of poly(4-acryloxybenzophenone thiosemicarbazone)-divinylbenzene resins, the uptake of $\mathrm{Cu}^{2+}$ and $\mathrm{Fe}^{2+}$ ions was $\mathrm{pH}$ dependent and the percent metal ion uptake increases with a rise in $\mathrm{pH}$ of the solution from 7 to 11 . At $\mathrm{pH} 7$ the amount of metal ion uptake was 12 and $11 \%$, respectively for $\mathrm{Cu}^{2+}$ and $\mathrm{Fe}^{2+}$ ions and at $\mathrm{pH} 10$ the amount of metal ion uptake was 74 and $46 \%$, respectively for $\mathrm{Cu}^{2+}$ and $\mathrm{Fe}^{2+}$ ions. The percent metal ion uptake by poly (4-acryloxybenzophenone thiosemicarbazone)divinylbenzene resins and the present resins are presented in table 4.

Table 4. Percentage metal ion uptaken and time taken for maximum uptake of metal ions.

\begin{tabular}{|c|c|c|c|c|c|c|c|c|c|}
\hline \multirow[b]{3}{*}{$\mathrm{pH}$} & \multicolumn{4}{|c|}{$\begin{array}{l}\text { Poly(4-acryloxybenzophenone } \\
\text { thiosemicarbazone)-divinylbenzene resins }\end{array}$} & \multirow[b]{3}{*}{$\mathrm{pH}$} & \multicolumn{4}{|c|}{$\begin{array}{l}\text { Poly[(4-acryloxy acetophenone)- } \\
\text { divinylbenzene] benzoyl hydrazone resins }\end{array}$} \\
\hline & \multicolumn{2}{|c|}{$\begin{array}{l}\text { Time taken for maximum } \\
\text { uptake of metal ion, minutes }\end{array}$} & \multicolumn{2}{|c|}{$\%$ metal ion uptake } & & \multicolumn{2}{|c|}{$\begin{array}{l}\text { Time taken for maximum } \\
\text { uptake of metal ion, minutes }\end{array}$} & \multicolumn{2}{|c|}{$\%$ metal ion uptake } \\
\hline & $\overline{\mathrm{Cu}^{2+}}$ & $\mathrm{Fe}^{2+}$ & $\mathrm{Cu}^{2+}$ & $\mathrm{Fe}^{2+}$ & & $\overline{\mathrm{Cu}^{2+}}$ & $\mathrm{Fe}^{2+}$ & $\mathrm{Cu}^{2+}$ & $\mathrm{Fe}^{2+}$ \\
\hline- & - & - & - & - & 3.6 & 50 & 60 & 27.6 & 29.6 \\
\hline- & - & - & - & - & 4.6 & & & 27.8 & 29.8 \\
\hline- & - & - & - & - & 5.6 & & & 28.2 & 29.9 \\
\hline 7 & 60 & 90 & 12 & 11 & - & & & - & - \\
\hline 8 & & & 19 & 19 & 8.2 & & & 28.1 & 30.2 \\
\hline 9 & & & 69 & 43 & 9.2 & & & 27.7 & 30.2 \\
\hline 10 & & & 74 & 46 & 10.1 & & & 27.7 & 30.1 \\
\hline 11 & & & - & 48 & - & - & - & - & - \\
\hline
\end{tabular}


It is observed that the uptake of metal ions by the present resins is independent of $\mathrm{pH}$ as compared with poly(4-acryloxybenzophenone thiosemicarbazone)-divinylbenzene resins. Further, the percent metal ion uptake by the present resins at $\mathrm{pH} 8.2$ is greater when compared to poly(4-acryloxybenzophenone thiosemicarbazone)-divinylbenzene resins. Whereas at $\mathrm{pH}$ 9 and 10 the percent metal ion uptake by poly (4-acryloxybenzophenone thiosemicarbazone)-divinylbenzene resins was greater than the present resins.

\subsection{Reusability of complexed AAP-DVB functionalized resin}

The most important advantage of chelating resin is their possible reuse after a particular process. The resin, once used, can be returned to its original form by desorbing the complexed metal ions with hydrochloric acid. The metal-free resin can be reused after washing with water several times. The recycling of the purified resin with the addition of $\mathrm{Cu}$ (II) and $\mathrm{Fe}$ (II) solution results in the intake of almost the same amount of respective metal ions as initially adsorbed. The process was repeated four times. The retention of the initial capacity, even after four cycles of repeated operations, suggests that the resin can be used several times without any reduction in capacity. Here, it is noteworthy that if the resin defunctionalized on acid treatment, it could be subjected to functionalization again. The BH modified polymer is insoluble in hydrochloric acid. During treatment with acid the $\mathrm{BH}$ moiety may detach from the polymer. But the poly[((AAP)-DVB)] is insoluble in $\mathrm{HCl}$. It can be separated by decantation of acid solution and can be refunctionalized with $\mathrm{BH}$ after a thorough wash with water. The metal ion can be recovered by concentrating the acid solution.

\section{Conclusions}

Suspension polymerization of AAP using BPO as catalyst and DVB as a cross-linking agent was carried out. The BH ligand was attached to the carbonyl functional group and the resulting ligated polymer used to prepare polymer-metal complexes. IR spectral studies showed that the azomethine nitrogen and benzoyl carbonyl group and chloride/sulphate anions were involved in coordination to the metal ions such as $\mathrm{Cu}$ (II) and $\mathrm{Fe}(\mathrm{II})$. Elemental analysis confirmed that the percentage of functionalization was $51 \%$, while the metallation was $28 \%$ and $30 \%$ for $\mathrm{Cu}(\mathrm{II})$ and $\mathrm{Fe}(\mathrm{II})$ complexes, respectively. The EPR spectra of the $\mathrm{Cu}$ (II) complex showed that the bonds are covalent in nature.
Thermal studies were carried out and the thermal dissociation patterns discussed. SEM photographs indicate the success of suspension polymerization. A bead structure was observed for the polymers. The maximum uptake efficiency for the metal ions was determined. The reusability of the polymer ligand was tested and it was shown that even after four cycles, the efficiency of the uptake was not altered.

\section{Acknowledgements}

The authors thank the University Grants Commission (UGC), New Delhi for financial support in the form of a Major Research Project. The authors also thank University Grants Commission, New Delhi and Department of Science and Technology (DST), New Delhi for funding the department through SAP and FIST programmes, respectively. The authors also thank the Regional Sophisticated Instrumentation centres of Indian Institute of Science, Bangalore and Indian Institute of Chemical Technology, Hyderabad and Central University, Hyderabad, India for providing the analytical data.

\section{References}

1. Block B T 1970 Inorg. Macromol. Rev. 1115

2. Bailar Jr J C 1978 Organometallic polymers (eds) C E Carraher Jr, J E Sheats and C V Pittman Jr (New York: Academic)

3. Merrifield R B 1965 Science 150178

4. Neckers D C 1975 J. Chem. Educ. 52695

5. Li W, Coughlin M, Albright R L and Fish R H 1995 React. Funct. Polym. 2889

6. Jovanovic S M, Nastasovic A, Jovanovic N N, Jeremic K and Savic Z 1994 Angew. Makromol. Chem. 219161

7. Jovanovic S M, Nastasovic A, Jovanovic N N and Jeremic K 1996 Mater. Sci. Forum. 214155

8. Sam Roman J, Madruga E L and Pargada L $1987 \mathrm{~J}$. Polym. Sci. Polym. Chem. Ed. 25203

9. He B, Su J, Li M and Wang L 1998 Shiyou. Huayong. 17668 (CA: 110:156404k)

10. Jiang W, Huang W and Zong H 1988 Fenzi Cuihua. 2 202

11. Menger F M and Tsuno T 1989 J. Am. Chem. Soc. 111 4903

12. Wiley R H and Clevenger R L 1962 J. Med. Pharm. Chem. 51876

13. Montegazza P, Panchiane F and Cavalind G 1961 Antibiot. Chem. 11405

14. Katyal M and Dutt J 1975 Talanta 22156

15. Babaiah O, Rao C K, Reddy T S and Reddy V K 1996 Talanta 43551

16. Babaiah O, Reddy P R, Reddy V K and Reddy T S 1999 Indian J. Chem. Sect. A. 381035

17. Babaiah O, Reddy P R, Reddy V K and Reddy T S 2004 J. Indian Chem. Soc. $\mathbf{8 1} 670$ 
18. Gangadharappa M, Reddy P R, Reddy V K and Reddy T S 2004 J. Indian Chem. Soc. 81525

19. Reddy V K, Thippaiah J, Rao C K, Reddy P R and Reddy T S 1999 J. Indian Chem. Soc. 76275

20. Vogel A I 1978 A text book of quantitative inorganic analysis (London: Longman)

21. Weiliao I and Eichinger B E 1990 J. Polym. Sci. Part A Polym. Chem. 28559

22. Bender M L and Figueras J 1953 J. Am. Chem. Soc. 75 6304

23. Torikai A, Takeuchi A, Nagaya S and Fueki K 1986 Polym. Photochem. 7279

24. Cunliffe A V 1978 Developments in polymer characterization-1, Chapter $1{ }^{13}$ C NMR spectroscopy of polymers (ed) J V Dawkins (London: Applied science)

25. Schaefer J and Stejskal E O 1979 Topics in carbon-13 NMR spectroscopy, Chapter 4, Vol. 3. High resolution ${ }^{13}$ C NMR of solid polymers (ed) L C George (New York: Wiley Interscience)

26. Bovey F A 1976 Structural studies of macromolecules by spectroscopic methods Chapter 10, High-resolution carbon-13 studies of polymer structure (ed) K J Ivin (New York: John Wiley \& Sons)

27. Rao B S, Modec P J and Marechal B C 1987 Macromol. Soc. Chem. A 24719
28. Okawa H, Tokii T, Noraka N, Muto Y and Kida S 1973 Bull. Chem. Soc. Jpn. 461462

29. Prabhakar L D and Marysaral A 1997 Polymer Int. 42 149

30. Kaliyappam T and Kannan P 1994 J. Polym. Mater. 11 121

31. Bostop O and Jorgensen C K 1957 Acta Chem. Scand. 111223

32. Wendlandt W W 1964 Thermal methods of analysis (New York: Interscience)

33. Allen T 1981 Particle size measurement (New York: Chapman and Hall) third edition

34. Barth H 1984 Modren methods of particle size analysis (New York: Wiley)

35. Arshady R J 1989 Microencapsulation 61

36. Kun K A and Kunin P 1968 J. Polym. Sci. Polym. Chem. 72689

37. Sederal W L and Dejong G J 1973 J. Appl. Polym. Sci. 172835

38. Torse R and Rieman V 1961 J. Phys. Chem. 651821

39. Mart Suzura M and Wadachi Y 1975 Bull. Chem. Soc. J. Pr. 483456

40. Nishide H, Deguchi J and Suchida E T 1977 Polym. Sci. Poly. Chem. Ed. 153028

41. Prabhakar L D, Uma M and Palanivelu C B 1992 J. Polym. Mater. 9185 